\title{
WORK-LIFE BALANCE KONSULTAN PAJAK DI KANTOR KONSULTAN "X” DI SURABAYA
}

\author{
Thalia Febiola Putri Sunardi \\ Universitas Surabaya \\ thaliafebiola99@gmail.com \\ Yenny Sugiarti \\ Universitas Surabaya \\ yenny_s@staff.ubaya.ac.id
}

\begin{abstract}
This study aims to determine the work-life balance and worker satisfaction for his work as a tax consultant. Factors that can affect the work-life balance are work environment, flexibility, financial factors, and work culture. The object of this research is " $X$ " Tax Consultant Office in Surabaya. This study used qualitative methods using semi-structured interview and direct observation. Based on the result of interviews and observations obtained result that flexibility and work environment have a role in determining work-life balance this is also supported by work environment and work culture provided by " $X$ " Tax Consultannt Office. The results showed that there were 2 conditions of work on tax consultants where there was a balance between work and personal life during the low season and imbalance during the peak season, however the consultants were satisfied with the overall work-life balance they were carrying out.
\end{abstract}

Keywords: work-life balance: flexibility: work culture and environment: tax consultant.

\section{PENDAHULUAN}

Keseimbangan antara kehidupan dan pekerjaan menjadi bagian yang penting untuk dipertimbangkan. Work-life balance merupakan sebuah konsep mengenai keseimbangan antara ambisi, karir, dan pekerjaan yang dilakukan dengan kebahagiaan, keluarga, waktu luang, serta perkembangan spiritual. Perusahaan yang tidak memperhatikan kebutuhan karyawannya akan kualitas kehidupan dan pekerjaan yang baik maka cenderung sulit mempertahankan karyawannya dikarenakan mereka akan lebih memilih berpindah ke tempat lain dimana mereka merasa lebih dihargai. (Cascio dan Boudreu, 2011)

Apabila seorang pekerja merasa nyaman dan mampu menciptakan keseimbangan dalam pekerjaan dan kehidupannya, maka dia akan menggunakan waktu kerjanya dengan produktif serta memberikan pelayanan terbaik. Terciptanya work-life balance akan membuat lingkungan kerja lebih menyenangkan, disiplin, kualitas kerja yang unggul serta gairah kerja menuju prestasi puncak. 
Penelitian yang dilakukan oleh Stevan dan Shiva (2013) mengenai keseimbangan antara pekerjaan dan kehidupan pada pekerja kontrak di Jerman menunjukkan bahwa disatu sisi kontrak kerja merupakan tantangan bagi keseimbangan antara kehidupan dan pekerjaaan tetapi disisi lain menawarkan kemungkinan bekerja secara fleksibel dan memungkinkan keseimbangan kerja yang lebih baik. Sedangkan Norfadzilah, dkk (2016) menunjukan bahwa faktor lingkungan kerja memiliki peran penting untuk mengembangkan work-life balance karyawan.

Konsultan pajak merupakan salah satu pekerjaan yang cukup banyak dibutuhkan oleh masyarakat mengingat hampir setiap orang di Indonesia tidak terlepas dari pajak, baik itu pajak penghasilan maupun pajak pertambahan nilai yang dapat ditemui sehari-hari. Pekerjaan ini menuntut tenaga dan waktu dari pekerjanya untuk terus memperbaharui pengetahuannya mengenai peraturan perpajakan dan pelaksanaannya agar dapat mengatasi dan membantu klien dalam menyelesaikan kewajiban dan masalah perpajakannya.

Penelitian ini menggunakan metode wawancara langsung untuk mengetahui keseimbangan waktu kehidupan kerja, kepuasan karyawan atas pekerjaan, dan keputusan karyawan untuk bertahan atas pekerjaan tersebut. Kantor Konsultan " $\mathrm{X}$ ” sebagai salah satu kantor akuntan publik ternama yang menyediakan jasa konsultan pajak menuntut karyawannya untuk mampu bekerja dengan tingkat global, secara profesional, mobilitas tinggi, dan hasil kerja yang berkualitas, dimana sistem kerjanya berdasarkan kontrak yang dibuat dengan klien. Oleh karena itu penelitian ini ingin mengetahui dan memahami keseimbangan waktu kehidupan kerja dan kepuasan karyawan tersebut sebagai seorang konsultan pajak di kantor konsultan "X" dalam tuntutan pekerjaannya dan kehidupan pribadinya.

\section{LANDASAN TEORI}

\section{Keseimbangan Kehidupan Kerja (Work-Life Balance)}

Menurut Hudson (2005), pengertian work-life balance dalam arti luas ialah sebagai tingkat keterlibatan yang memuaskan antar berbagai peran dalam kehidupan manusia. Studi 
mengenai keseimbangan kehidupan kerja melibatkan kemampuan seseorang untuk mengelola tuntutan kehidupan dari berbagai segi secara bersamaan. Sedangkan Sturges dan Guest (2014) mendefisinikan work-life balance sebagai kemampuan individu untuk menjalankan permintaan ditempat kerja seta memenuhi komitmen dalam keluarga dan aktivitas sosial.

Cascio (2000) yang mengatakan work-life balance sebagai sebuah keuntungan maupun kondisi kerja yang di sponsori oleh perusahaan yang membantu karyawan dalam menyeimbangkan pekerjaan dan tuntutan kehidupan diluar pekerjaannya.

Norfadzilah, Hairunnisa, dan Narehan (2016) menyebutkan work-life balance sebagai rasa keseimbangan karyawan terhadap pekerjaan, keluarga, dan kehidupan mereka sendiri untuk mempertahankan kualias kinerja yang tinggi serta menjaga hubungan yang sehat dan keluarga. Sedangkan menurut Jarrod,dkk (2014) work-life balance merupakan pendekatan yang berpusat pada sudut pandang yang mempertimbangkan keseimbangan antara kerja dan hidup menjadi sebuah konsep yang holistik dan unik untuk setiap orang, bergantung pada nilai, prioritas dan sasaran dalam hidupnya.

Dalam merespon meningkatnya permintaan akan work-life balance, banyak organisasi menawarkan kebijakan untuk meningkatkan fleksibilitas dalam pengaturan kerja mereka. Kristen dan Tammy (2010), mendefinisikan fleksibilitas pengaturan kerja sebagai alternatif pekerjaan yang harus diselesaikan diluar batas dari hari kerja standar. Fleksibilitas pengaturan kerja dapat ngacu pada fleksibilitas waktu kerja maupun fleksiilitas lokasi pekerjaan. (Kristen dan Tammy, 2007).

Berdasarkan beberapa definisi work-life balance yang sudah disebutkan di atas, dapat disimpulkan bahwa work-life balance merupakan sebuah konsep yang berpusat pada persepsi unik bagi setiap orang mengenai keseimbangan antara pekerjaannya dan kehidupan pribadi diluar pekerjaannya.

Beberapa aspek yang digunakan untuk mengukur work-life balance seperti yang dikemukakan oleh Hudson (2005) yaitu time balance, involvement balance, dan satisfaction balance. Sedangkan beberapa faktor yang mempengaruhi work-life balance seorang individu 
diantaranya menurut Pouluse dan Sudarsan dalam Wahyuni (2018) ialah faktor individual, organisasional, lingkungan dan juga faktor-faktor lainnya.

\section{Kepuasan Kerja}

Menurut Gibson, dkk (2013) kepuasan kerja merupakan sebuah sikap yang dimiliki para pekerja mengenai pekerjaan yang mereka lakukan. Sedangkan Hasibuan (200:202) mengatakan bahwa kepuasan kerja merupakan sebuah sikap dari emosi positif yang menyenangkan dan mencintai pekerjaan yang dilakukannya. Peter dkk (2018) mengatakan bahwa kepuasan kerja adalah fungsi kepuasan dengan faktor lain dalam kehidupan dimana setiap individu memiliki fungsi kepuasan yang berbeda antara satu dengan yang lainnya.

Tay, dkk (2013) serta Abdul, Hairunnisa, dan Hassan (2016), mengungkapkan bahwa terdapat beberapa faktor yang mempengaruhi kepuasan kerja seseorang dalam menjalankan pekerjaannya, diantaranya kebijakan fleksibilitas, lingkungan pekerjaan, jam kerja, serta budaya perusahaan.

\section{METODE PENELITIAN}

Penelitian ini menggunakan metode pendekatan kualitatif untuk mengetahui kejadian dan fenomena yang terjadi. Penulis membagi main research question pada penelitian ini menjadi beberapa mini research question untuk mengetahui keseimbangan kehidupan kerja seorang konsultan pajak. Objek penelitian yang digunakan oleh penulis pada penelitian ini ialah pekerja konsultan pajak pada KAP “X” dari tingkat junior consultant hingga manager.

Dalam mengumpulkan data yang dibutuhkan, penulis menggunakan metode pengumpulan data dengan melakukan wawancara, observasi secara langsung dan analisis data. Wawancara dilakukan secara langsung dengan menggunakan metode semi structured kepada masing-masing narasumber yaitu 10 orang konsultan pajak dengan berbagai tingkatan mulai dari junior konsultan hingga manager.

Observasi secara langsung dilakukan terhadap kegiatan yang berkaitan dengan profesi seorang konsultan pajak. Tujuan obeservasi yang dilakukan adalah untuk melihat work-life balance yang terjadi di Kantor Konsultan Pajak “X”. Observasi dilakukan menggunakan 
metode participant observation, dimana penulis terlibat aktif dan melakukan pengamatan secara langsung. Sebelum melakukan proses analisis data, terlebih dahulu dilakukan kajian sekilas atas dokumen yang diperlukan, kemudian dilakukan penyesuaian atas data-data yang diperoleh, dan membandingkan data untuk diolah lebih lanjut hingga dapat ditarik hasil dan kesimpulan.

\section{HASIL DAN PEMBAHASAN}

\section{Fleksibilitas di Kantor Konsultan " $\mathrm{X}$ ”}

Kantor konsultan "X” memberikan fleksibilitas bagi konsultannya dalam mengerjakan pekerjaannya. Hal ini bertujuan untuk membantu pekerja dalam mengerjakan pekerjaannya dengan nyaman sehingga dapat memperoleh hasil kerja yang lebih baik. Bentuk fleksibilitas di kantor konsultan “ $X$ ” seperti:

a. Tempat kerja

Kantor Konsultan Pajak “X” memperbolehkan para konsultannya untuk membawa pulang pekerjaan yang sedang mereka kerjakan. Para konsultan dalam menyelesaikan pekerjaan mereka yang belum selesai tidak harus di kantor dan melakukan lembur melainkan mereka dapat menyelesaikannya di rumah mereka.

b. Jam kerja

Konsultan di Kantor Konsultan “ $X$ ” ini bekerja dengan waktu yang cukup fleksibel. Hal ini dapat dilihat dimana para konsultan masuk kantor antara pukul 9 hingga setengah 10 pagi meskipun secara peraturan kantor seharusnya mereka datang pada pukul setengah 9 pagi. Begitu juga dengan jam pulang kantor dimana secara peraturan para konsultan pulang pada pukul setengah 6 sore tetapi pada praktiknya mereka pulang diatas jam setengah 6 sore yang dapat disesuaikan dengan jam masuk kantor mereka dengan total jam kerja 8 jam sehari.

c. Istirahat Siang

Kantor Konsultan Pajak “X” memberikan fleksibilitas jam dan tempat makan dan istirahat siang bagi para konsultannya. Jam istirahat dan makan siang para konsultan pada umumnya berlangsung selama 2 jam meskipun seharusnya secara 
peraturan tertulis 1 jam. Selain itu tidak terdapat batasan tempat para konsultan melakukan makan siang. Para konsultan selalu makan diluar kantor pada hari jumat setiap minggunya. Terkadang untuk beberapa waktu pada hari-hari biasa seperti hari Senin sampai dengan Kamis para konsultan di Kantor Konsultan “X” juga dapat makan diluar kantor.

d. Ijin cuti

Kantor Konsultan " $\mathrm{X}$ ” memberikan kemudahan bagi para konsultannya apabila ingin mengambil cuti liburan maupun ijin tidak masuk karena alasan lainnya. Selain para konsultan memiliki jatah cuti pertahunnya sebanyak 12 hari, para konsultan tetap dapat mengambil ijin untuk tidak masuk meskipun jatah cuti yang mereka miliki sudah habis dengan konsekuensi pemotongan gaji.

e. Pengisian Time Sheet

Kantor Konsultan ini tidak melakukan kontrol untuk memantau jam kerja konsultannya melainkan memberikan kebebasan bagi seluruh konsultannya untuk mengisi sendiri time sheet jam kerja mereka secara online melalui software khusus dari kantor.

f. Bekerja

Kantor Konsultan "X” memberikan kebebasan bagi konsultannya untuk bekerja dengan cara kreatif masing-masing individu selama hasil yang dihasilkan sesuai dengan yang diharapkan. Setiap konsultan di kantor konsultan "X" bebas untuk memberikan pendapat atas apa yang mereka pikirkan maupun memberikan tanggapan atas pendapat orang lain.

Terlihat bahwa Kantor Konsultan " $\mathrm{X}$ ” menerapkan sistem yang bersifat result control dan berorientasi pada hasil dimana para konsultan dapat bekerja dengan jam, tempat, pengisian time sheet, maupun cara kerja yang lebih fleksibel selama pekerjaan dapat terselesaikan dengan baik dan tepat waktu. 


\section{Pembagian Kehidupan Kerja, Pribadi dan Sosial Konsultan Pajak}

Berdasarkan hasil wawancara beberapa konsultan membagi waktu mereka untuk pekerjaan mereka dan kehidupan pribadi dimana mereka membagi waktu hari senin sampai dengan jumat sebagai waktu untuk bekerja dan akhir pekan yaitu hari sabtu dan minggu sebagai hari untuk kehidupan pribadi seperti keluarga. Selain itu mereka juga memanfaatkan waktu sepulang kerja untuk kehidupan pribadinya. Tetapi tidak semua konsultan melakukan pembagian waktu antara pekerjaan dan kehidupannya.

Sebagian besar dari mereka yang sudah berkeluarga tidak melakukan pembagian waktu secara khusus. Mereka yang berkeluarga cenderung tidak membagi waktu mereka dikarenakan kenyataan mengenai kewajiban keluarga yang membuat pembagian waktu menjadi lebih sulit. Tidak adanya batasan ataupun pembagian waktu secara signifikan antara kantor dan keluarga membuat mereka yang telah menikah mampu memenuhi kewajiban perannya dengan lebih baik dimana mereka dapat menggabungkan banyak tugas untuk memenuhi pekerjaan serta tanggungjawab mereka sebagai seorang konsultan dan juga peran sebagai ayah serta suami maupun ibu serta istri.

Terdapat pembagian musim atas pekerjaan yang mereka lakukan, dimana ada low season dan peak season. Low season merupakan kondisi dimana tidak terdapat terlalu banyak enggagement, pada saat low season ini enggagement klien biasanya berupa sengketa perpajakan. Sedangkan peak season merupakan kondisi dimana terdapat banyak enggagement berupa pemenuhan kewajiban klien seperti berupa SPT yang menuntut banyaknya pekerjaan dengan deadline yang sama.

Pada saat low season, para konsultan jarang lembur dan hanya melakukan lembur untuk beberapa kondisi aja kalau ada sesuatu yang penting. Berbeda halnya pada saat peak season, para konsultan dituntut untuk lembur dalam menyelesaikan pekerjaannya dikarenakan deadline yang mepet dan jumlah pekerjaan yang cukup banyak. Seorang konsultan pada saat peak season dapat lembur hingga diatas jam 12 malam bahkan hingga

Jurnal Akuntansi dan Teknologi informasi (JATI) Vol. 13 No. 1 Maret 2019 
pagi tiba. Peak season ini berlangsung hanya selama beberapa bulan saja yaitu mulai bulan Desember hingga April dimana waktu lembur terjadi antara bulan Maret dan April.

Pekerjaan sebagai konsultan pajak memiliki karaktestik pekerjaan dengan jam kerja yang cukup yang fleksibel, selain itu terdapat tuntutan pekerjaan untuk ke luar kota terkadang perlu untuk dilakukan baik itu berupa vouching tax invoice hingga sidang sengketa pajak. Berdasarkan hasil penelitian yang dilakukan, frekuensi untuk melakukan tugas diluar kota jarang dilakukan hanya untuk kondisi tertentu dan enggagement tertentu saja. Perjalananpun tidak memakan waktu yang cukup lama hanya sekitar 1 hingga 2 hari saja tergantung pekerjaan yang dilakukan.

Meskipun dengan adanya tuntutan untuk keluar kota maupun lembur menambah jam kerja dan beban kerja yang dijalani oleh para konsultan di kantor ini sehingga waktu yang mereka curahkan untuk bekerja jauh lebih banyak, tetapi tuntutan untuk keluar kota maupun lembur ini tidak berlangsung lama.

Dapat disimpulkan bahwa para konsultan pajak yang telah berkeluarga lebih cenderung tidak melakukan pembagian waktu dalam kehidupannya. Mereka yang telah berkeluarga cenderung lebih fleksible dalam menjalani kehidupannya. Selain itu, pada penelitian ini juga terlihat bahwa pada kondisi low season kehidupan para konsultan pajak cenderung lebih seimbang dimana mereka dapat menyeimbangkan pekerjaan dan juga tuntutan di luar pekerjaannya sebagai seorang konsultan pajak. Berbeda halnya pada saat peak season, kehidupan para konsutan menjadi tidak seimbang dikarenakan mereka harus lembur jauh lebih banyak dikarenakan jumlah pekerjaan yang meningkat yang menyebabkan pemenuhan tuntutan kehidupan diluar pekerjaannya menjadi lebih sulit terpenuhi.

\section{Persepsi Work-Life Balance Konsultan Pajak Terhadap Keseimbangan Pekerjaan dan Kehidupannya.}

\section{Work-Life Balance dari Persepsi Pekerjaan Konsultan Pajak}

Para konsultan merasa bahwa tuntutan pekerjaan untuk lembur yang dilakukan ini merupakan bentuk dari tanggungjawab mereka terhadap pekerjaan yang mereka lakukan 
sebagai seorang konsultan pajak dan mereka juga tidak sepanjang waktu melakukan lembur hanya pada saat peak season dan kondisi tertentu saja sehingga mereka tidak merasa terganggu meskipun harus melakukan lembur. Begitu juga dengan tuntutan pekerjaan untuk melakukan perjalan ke luar kota para konsultan sudah mempersiapkan diri sebelum mereka memasuki dunia kerja seorang konsultan pajak sehingga mereka tidak merasa terganggu dengan adanya pekerjaan yang menuntut mereka untuk ke luar kota.

Faktor lainnya yang dapat mempengaruhi work-life balance ialah faktor lingkungan, hal ini dikemukakan oleh Pouluse dan Sudarsan dalam Wahyuni (2018). Pada penelitian ini dilihat bahwa kondisi lingkungan pada kantor konsultan pajak " $\mathrm{X}$ ” ini cukup nyaman. Pekerjaan dengan sistem tim yang membutuhkan kerjasama antar anggota membuat mereka merasa nyaman karena tidak harus bekerja sendiri, selain itu para senior dan manager juga memberikan bimbingan terhadap para bawahannya begitu juga bawahannya yang juga turut memberikan bantuan kepada para atasannya. Proses bekerja yang saling memberikan bantuan satu sama lain ini memberikan kondisi lingkungan dimana para pekerja sebagai konsultan pajak merasa nyaman atas pekerjaan yang mereka lakukan.

\section{Work-Life Balance dari Persepsi Kehidupan Diluar Pekerjaan Konsultan Pajak.}

Setiap orang pasti memiliki kepentingan pribadi salah satu contohnya seperti hobi yang merupakan kegiatan yang akan dilakukan seseorang untuk menyenangkan diri. Pada hasil penelitian terlihat pada kondisi peak season, maka para pekerjan konsultan pajak di kantor konsultan " $X$ ” cenderung kesulitan dalam menjalankan hobi yang dimilikinya. Hal ini dikarenakan mereka harus bekerja dalam waktu yang lebih lama dibandingkan yang baisa mereka lakukan pada saat low season. Sedangkan secara umum pada saat low season para konsultan tetap dapat menajalakan kehidupan pribadinya salah satu contohnya seperti menjalankan hobi yang dimilikinya seimbang dengan mereka menjalankan pekerjaannya sebagai konsultan pajak.

Para konsultan pajak selain perlu menjalankan pekerjaannnya dengan baik, mereka juga memiliki peran lain dalam kehidupan baik mulai dari seorang teman, anak, ayah, ibu, 
suami, maupun istri. Keseimbangan antara pekerjaan dan kehidupan dapat tercipta dengan mempertahankan kualitas kerja dan menjaga hubungan dengan keluarga, teman, dan orangorang lain dalam kehidupannya diluar pekerjaannya sebagai seorang konsultan pajak.

Berdasarkan hasil penelitian yang dilakukan melalui wawancara dan observasi terlihat bahwa para konsultan memiliki kehidupan diluar pekerjaan mereka yang cukup baik. Hal ini dapat dilihat dari hubungan baik yang mereka jalin dengan orang-orang sekitarnya. Meskipun para konsultan lebih banyak menghabiskan waktu mereka untuk bekerja di kantor, tetapi disisi lain mereka tetap dapat menjaga dan membangun hubungan baik dengan orang disekitarnya.

Meskipun sekilas terlihat bahwa kehidupan dan pekerjaan para konsultan pajak cukup seimbang dimana mereka dapat menjalankan peran dan kehidupannya diluar pekerjaannya sebagai seorang konsultan pajak, tetapi keseimbangan ini terjadi pada saat low season dimana hal yang berbeda terjadi pada saat peak seaon. Pada saat peak season, kehidupan para konsultan pajak cenderung berubah. Hal ini disebabkan karena mereka harus melakukan pekerjaan jauh lebih banyak serta memakan waktu lebih lama dimana mereka juga perlu banyak melakukan lembur yang menambah waktu kerja mereka menjadi lebih panjang.

Ketidakseimbangan antara pekerjaan dan kehidupan konsultan pajak dapat dilihat dari reaksi orang tua dari saudari ER, dimana saudari ER mengatakan,

"Ya awal-awal shock seh papaku ae sampe waktu itu papaku sampe tidur sampe bangun lagi aku itu jek dek depan laptop sampe papaku kmu resignno ae terus yo awal-awal kayak gitu terus suwe-suwe wes biasa liak aku sampe jam 4 pagi dek depan laptop yo wes biasa."

Saudara RB juga mengatakan,“Kalau orang tua ga mungkin marah soalnya di malang jarang cerita, tapi yo ga masalah ngerti pasti dee. Mungkin ya bakal masalah bek pacar kan ktemune kurang, komunikasine."

Terlihat bahwa saudara RB jarang menceritakan pekerjaan yang dilakukannya sebagai seorang konsultan pajak kepada kedua orang tuanya dikarenakan ia tidak ingin membuat Jurnal Akuntansi dan Teknologi informasi (JATI) Vol. 13 No. 1 Maret 2019 
orang tuanya khawatir melihat pekerjannya pada saat peak season. Selain itu ketidakseimbangan juga terlihat dari ungkapan saudara RB dimana adanya kemungkinan terjadinya permasalahan dengan pacarnya dikarenakan banyaknya pekerjaan yang harus dilakukan pada saat peak season yang menyebabkan kurangnya waktu untuk bertemu dan komunikasi menjadi sedikit terganggu.

Dapat disimpulkan bahwa pada saat low season terjadi keseimbangan antara pekerjaan dan kehidupan pribadi para konsultan pajak tetapi lain halnya pada saat peak season dimana terdapat ketidakseimbangan antara pekerjaan dan kehidupan pribadi para konsultan pajak pada saat peak season. Para konsultan pajak mengaku kesulitan menjalankan hobinya pada saat peak season dan juga selain itu terlihat dari reaksi negatif orang terdekat para konsultan pajak pada saat peak season. Hal ini dikarenakan beban kerja yang lebih banyak dan waktu kerja para konsultan pajak yang semakin panjang yang menyebabkan waktu untuk kehidupan pribadi mereka menjadi jauh berkurang dan menjadi tidak seimbang.

\section{Kepuasan Konsultan Pajak Terhadap Work-Life Balance}

Norfadzilah, dkk (2016) mengatakan bahwa lingkungan dan tempat kerja merupakan tempat pertama untuk memastikan keseimbangan pekerjaan dan kehidupan karyawan agar kehidupan mereka tetap seimbang dan merasa senang dalam bekerja. Lingkungan kerja dan rasa senang dalam bekerja akan mendukung terciptanya work-life balance sehingga muncul kepuasan seseorang dalam menjalankan pekerjaan dan kehidupannya.

Pada penelitian ini terlihat bahwa para reponden yang merupakan konsultan pajak yang bekerja pada kantor konsultan " $\mathrm{X}$ ” mengaku cukup puas dengan work-life balance yang mereka rasakan selama bekerja sebagai konsultan di kantor konsultan pajak “ $X$ ” ini. Berdasarkan hasil wawancara dengan para responden yang merupakan konsultan pajak di kantor konsultan " $X$ ” terlihat bahwa sebagian besar dari para konsultan merasa cukup puas dengan pekerjaan mereka sebagai konsultan di kantor konsutan " $X$ ” ini. Beberapa faktor yang mempengaruhi kepuasan para konsultan ini diantaranya faktor lingkungan pekerjaan, budaya 
perusahaan, faktor sosial, faktor finansial, dan juga faktor organisasi dan manajemen pada kantor konsultan "X” ini.

Berdasarkan hasil wawancara dan observasi yang dilakukan, para konsultan di kantor konsultan " $\mathrm{X}$ " terutama merasa nyaman dan puas dengan lingkungan kerja dan hubungan sosial antara konsultan satu dengan yang lainnya. Hal ini terlihat dari perasaan nyaman atas lingkungan pekerjaan yang dirasakan oleh para konsultannya. Pekerjaan dengan sistem tim membuat mereka merasa nyaman karena tidak harus bekerja sendiri selain itu kondisi lingkungan yang terbuka dimana semua orang dapat menyempaikan pendapat dan pemikiran mereka membuat para pekerja dapat berkembang dan nyaman dalam mengutarakan pendapat dan pemikiran yang mereka miliki. Hubungan antar atasan manager, senior, maupun junior yang baik juga membantu mereka mengerjakan tugas mereka dengan rasa nyaman.

Selain itu, berdasarkan pengamatan yang dilakukan menunjukkan bahwa kantor konsultan pajak “X” memiliki budaya kerja yang baik. Para konsultan pajak di kantor ini memiliki sikap profesional dan bertanggungjawab dalam menjalankan kewajiban dan tugasnya. Mereka saling berbagi ilmu, pengetahuan, dan pendapat yang mereka miliki untuk membantu satu sama lain dalam menghadapi permasalahan dan untuk berkembang bersama. Budaya untuk bekerjasama, saling terbuka, kebebasan untuk mengemukakan pendapat, serta berkembang bersama menciptakan lingkungan yang nyaman bagi para konsultan di kantor konsultan "X" ini. Hal ini merupakan salah satu faktor yang menyebabkan para konsultan puas dengan pekerjaan mereka sebagai konsultan pajak di kantor konsultan "X”.

\section{KESIMPULAN}

Konsultan pajak di Kantor Konsultan Pajak “X” memiliki beberapa fleksibilitas. Salah satu diantaranya ialah jam kerja dimana para konsultan tidak sepenuhnya harus tepat waktu seperti yang tertulis pada peraturan kantor tetapi memiliki kelonggaran waktu dan jam kerja yang lebih fleksibel.

Hasil penelitian yang dilakukan terlihat bahwa sebagian besar dari para konsultan yang sudah berkeluarga tidak melakukan pembagian waktu dibandingkan mereka yang 
lajang. Hal ini dikarenakan dengan tidak adanya pembagian waktu yang signifikan maka para konsultan yang sudah berkeluarga menjadi lebih fleksible dan dapat memenuhi peran serta tanggung jawab mereka dengan lebih baik.

Pekerjaan sebagai konsultan pajak dibagi menjadi 2 kondisi yaitu low season dan peak season. Penelitian yang dilakukan di Kantor Konsultan Pajak "X” ini menunjukkan bahwa pada saat low season terjadi keseimbangan antara pekerjaan dan kehidupan pribadi para konsultan pajak tetapi lain halnya pada saat peak season dimana terdapat ketidakseimbangan antara pekerjaan dan kehidupan pribadi para konsultan pajak. Hal ini dikarenakan beban kerja yang lebih banyak dan waktu kerja para konsultan pajak yang semakin panjang yang menyebabkan waktu untuk kehidupan pribadi mereka menjadi jauh berkurang dan menjadi tidak seimbang.

Salah satu faktor yang mempengaruhi kepuasan work-life balance para konsultan ialah faktor lingkungan dan hubungan sosial dimana lingkungan yang yang terbuka dan saling membantu satu sama lain menciptakan rasa nyaman dan hubungan yang baik antar sesama rekan kerja. Jam kerja yang fleksibel menyebabkan para konsultan dapat bekerja dengan jam kerja yang lebih fleksibel meskipun pada kondisi tertentu dan pada saat peak season menuntut konsultan untuk lembur tetapi hal ini diimbangi dengan faktor finansial yang cukup mendukung seperti gaji, bonus lembur, dan juga fasilitas yang diberikan.

Selain itu Kantor Konsultan Pajak “X” memiliki budaya kerja yang baik dimana mereka saling berbagi ilmu, pengetahuan, serta tidak ragu untuk membantu satu sama lain dalam menghadapi kasus maupun permasalahan baik kasus dari klien maupun kasus pribadi diluar pekerjaan. Budaya kerja untuk berpikiran terbuka membuat setiap konsultan dapat menyampaikan pendapat dan pemikiran mereka baik mulai dari junior assistance hingga manajer sehingga mereka dapat berkembang bersama-sama. Hal ini menyebabkan para konsultan di kantor konsultan “ $\mathrm{X}$ ” merasa nyaman dalam bekerja sehingga muncul rasa puas dan mendukung terciptanya work-life balance mereka sebagai konsultan 


\section{DAFTAR PUSTAKA}

Accenture (2013). Accenture Research Finds Most Professionals Believe They Can "Have It All". https://newsroom.accenture.com/subjects/corporate-citizenship-philanthropy/accentureresearch-finds-most-professionals-believe-they-can-have-it-all.htm. (diakses pada 20 September 2018)

Agustina, Lidya. 2008. Pengaruh Work-Family Conflict Terhadap Job Sattisfaction dan Turnover Intention Pada Profesi Akuntan Publik. Jurnal Ilmiah Akuntansi, Vol 7, 100-116.

Badan Pusat Statistik. 2017. Perkembangan Angkatan Kerja Nasional 2015-2017. Jakarta Pusat: Badan Pusat Statistik.

Cascio, W, dan Boudreu, J. 2011. Investing People: Finanacial Impact of Human Resources. Ubited States. Of Amerika: Education Inc Publishing as FT Press.

Cascio, W. F. (2000). Costing human resources: The financialimpact of behavior in organizations 4th Edition. Cincinnati, OH: Southwestern.

Dini. 2013. Work-Life Balance. https://ifestyle.kompas.com/read/2013/03/08/1335020/quotworklife.balancequot.indikator.baru.kesuksesan. (diakses tanggal 10 September 2018)

Fisher, G. G., Bulger, C. A., dan Smith, C. S. 2009. Beyond Work and Family: A Measure of Work/Nonwork Interference and Enhancementll. Journal of Occupational Helath Psychology,14(4), 441-456.

Gibson, James L, Ivancevich, John. M., \& Donelly, James Jr. 2003. Organisasi dan Manajemen: Perilaku, Struktur dan Proses Jilid I. Jakarta: Erlangga.

Hasibuan, Drs. H. Malayu S.P.,2000. Manajemen Sumber Daya Manusia. Jakarta. Grasindo.

Hudson. 2005. The Case for Work/Life Balance: Closing the Gap Between Policy and Practice. Hudson Highland Group, Inc.

Jarrod, dkk. 2014. Ourcomes of Work-Life Balance on Job Satisfaction, Life Satisfaction and Mental Health: A Study Across Seven Cultures. Journal of Vocational Behavior, Vol 85, 361-373.

Kreitner, Robert dan Kinicki, Angelo de. 2013. Perilaku Organisasi Edisi Kelima. Jakarta: Salemba.

Kurniasari, Devi dan Abdul Halim. Pengaruh Lingkungan Kerja dan Iklim Organisasi Terhadap Komitmen Organisasi Melalui Kepuasan Kerja Karyawan pada Dinas Pasar Unit Pasar Tanjung Kabupaten Jember, Jurnal Ilmu Ekonomi. Mei 2013, Vol.8 No.2, hal.273-279

Luthans, Fred. 2006. Perilaku Organisasi. Yogyakarta. ANDI.

Machasin. 2015. Mencermati Perilaku Karyawan. http://www.riaupos.co/3674-opini-mencermatiperilaku-karyawan.html\#.VoicolLBuKE. Di unduh 22 September 2018. 
Menteri Keuangan Repubik Indonesia. 2014. Peraturan Menteri Keuangan Republik Indonesia Nomor 111/PMK.03/2014. https://www.ikpi.or.id/sites/default/files/peraturan_pajak/pmk111214.pdf. (diunduh 10 September 2018)

Ni Nyoman, Nyoman, dan Agus. 2017. Faktor-Faktor yang Mempengaruhi Kepuasan Kerja Karyawan The Legian Bali Hotel. Jurnal Kepariwisataan dan Hospitalitas. Vol. 1, No. 1.

Norfadzilah, Hairunnisa, dan Narehan. 2016. Measuring Reliability and Validity Instruments of Work Environment Towards Quality Work Life.Procedia Economix and Finance, Vol 37, 520-528.

Peter, Jolanda, dan Cornelius. 2018. Self-employment and Satisfaction with Life, Work, and Leisure. Journal of Economic Psychology. Vol. 64. No 73-88.

Stevan dan Shiva. 2013. Balance Between Work and Life: A Qualitative Study of German Contract Workers. European Management Journal, Vol 31, 250-262.

Wahyuni, Sri. 2018. Pengaruh Keseimbangan Kehidupan Kerja dan Kepuasan Kerja Terhadap Loyalitas Pegawai dan Guru: Studi pada Sekolah Swasta Bbarsari Kecamatan Pancur Batu. Fakultas Ilmu Sosial dan Ilmu Politik. Medan: Universitas Sumatera Utara.

Capalbo, F., Frino, A., Mollica, V. \& Palumbo, R. 2014. Accrual-based earnings management in state owned companies: Implications for transnational accounting regulation. Accounting, Auditing \& Accountability Journal, 27, 1026-1040.

Kieso, D. E., Weygandt, J. J., \& Warfield, T. D. (2012). Intermediate Accounting (14 ed.). United States of America: John Wiley \& Sons. 